\title{
Protecting intact forests requires holistic approaches
}

To the Editor - Watson et al. ${ }^{1}$ present a compelling case for setting aside intact forest landscapes (IFL), based on their exceptional values for biodiversity, mitigating climate change, indigenous societies and human health. Intact forests have higher environmental, cultural and biodiversity values than fragmented, managed or regenerating forests, and their strict protection from outside intervention should be a high priority for national and international policy. Keeping these special places intact requires minimizing all human impacts except those of the indigenous people who legitimately hold claim to the forest. This view places the need for strict conservation of species, habitats, ecosystem services, and natural and mineral resources above other components of the conservation and sustainable development agenda that prioritize human wellbeing. Ultimately, fulfilling human wellbeing rests on maintaining or restoring ecosystem service supply and conserving local biodiversity ${ }^{2,3}$.

An underlying premise of Watson et al.s paper $^{1}$ is that policies can be successfully developed and enforced to ensure the long-term protection of irreplaceable forest areas and their qualities. Yet the track record for government-mandated strict protection of intact natural areas is highly imperfect. Governments come and go, and many protected areas remain protected only on paper ${ }^{4}$. The factors responsible for reduction of IFL are not going to magically disappear based on a government decree or a resolution enacted by an international convention. Industrial timber extraction, agricultural expansion, energy production and mining have driven the reduction of IFL globally ${ }^{5}$. Viewing these drivers as threats that must be eliminated does not replace the need for negotiated, managed, holistic solutions to resolving societal conflicts over forest appropriation or resource exploitation ${ }^{6}$. As long as markets continue to demand these products, and their production cannot be effectively supplied from already deforested areas, these drivers will remain strong.

Narrowly focused conservation efforts based on strict protective policies often fail to achieve their goals, while demanding a high social $\operatorname{cost}^{7}$. The finding that reduction of IFL from 2000 to 2013 was lower inside than outside protected areas may largely be an artefact of the non-random distribution of protected areas within remote and largely inaccessible IFL ${ }^{5}$. Protected areas are safe from exploitation only when their collective resources as intact systems are valued above and beyond their immediate economic value. Maintaining and improving the integrity of IFL requires integrated and comprehensive policy reform focused on effective management and governance of forest landscapes and resources. This solution calls for a recognition of the values and contributions of diverse states and configurations of forests: intact and fragmented, old and young, managed and wild. Ideally, the distribution of these values should determine which areas are to be managed through strict protection and which areas can be locally managed for multiple purposes ${ }^{8}$. Conservation, forest management, land management and restoration need to be implemented in strategic ways to save our life support systems. If we fail to do so, we risk protecting the jewels in the safe while letting the house burn down.

Robin L. Chazdon

Tropical Forests and People Research Centre, University of the Sunshine Coast, Sippy Downs,

Queensland, Australia.

e-mail:rchazdon@usc.edu.au

Published online: 9 April 2018

https://doi.org/10.1038/s41559-018-0546-y

References

1. Watson, J. E. M. et al. Nat. Ecol. Evol 2, 599-610 (2018).

2. Gregersen, H., El Lakany, H. \& Blaser, J. Int. For. Rev. 19, 10-23 (2017).

3. Naeem, S., Chazdon, R., Duffy, J. E., Prager, C. \& Worm, B. Proc. R. Soc. B 283, 20162091 (2016).

4. Di Minin, E. \& Toivonen, T. BioScience 65, 637-638 (2015).

5. Potapov, P. et al. Sci. Adv. 3, el600821 (2017).

6. Chan, K. et al. Conserv. Biol. 21, 59-68 (2007).

7. Oldekop, J., Holmes, G., Harris, W. \& Evans, K. Conserv. Biol. 30, 133-141 (2016).

8. Sayer, J. A. \& Margules, C. Land 6, 41 (2017).

Competing interests

The author declares no competing interests. 